\title{
Impact of Hepatic Encephalopathy in Cirrhosis on Quality-of-Life Issues
}

\author{
Sara Montagnese ${ }^{1} \cdot$ Jasmohan S. Bajaj ${ }^{2}$
}

Published online: 31 January 2019

(c) The Author(s) 2019

\begin{abstract}
Hepatic encephalopathy (HE) has a major impact on health-related quality of life (HRQOL) in patients, which has clinical and psychosocial consequences. HRQOL in cirrhosis has been measured by generic and liver-specific instruments, with most studies indicating a negative impact of HE. HRQOL abnormalities span daily functioning, sleep-wake cycle changes, and the ability to work. Of these, sleep-wake cycle changes have a major effect on HRQOL, which remains challenging to treat. The personal effect of HRQOL is modulated by the presence of HE, the etiology of cirrhosis, and cognitive reserve. Patients with higher cognitive reserve are able to tolerate HE and its impact on HRQOL better than those with a poor cognitive reserve. The impact of HRQOL impairment is felt by patients (higher mortality and poor daily functioning), as well as by caregivers and families. Caregivers of patients with HE bear a major financial and psychological burden, which may affect their personal health and longevity.
\end{abstract}

\section{Introduction}

Health-related quality of life (HRQOL) is one of the most important patient-reported outcomes for clinical trials and investigations. In patients with cirrhosis, the role of hepatic encephalopathy (HE), either overt or covert (the former being diagnosed clinically based on the West Haven criteria grade II or higher [1-3], and the latter including grade I according to the West Haven criteria and abnormalities on neuropsychological/neurophysiological testing [1]), has a major impact on HRQOL. This manuscript only focuses on HRQOL and HE; the impact of therapies on HRQOL change are discussed elsewhere in this supplement.

Sara Montagnese

sara.montagnese@unipd.it

$\triangle$ Jasmohan S. Bajaj

Jasmohan.bajaj@vcuhealth.org

1 Department of Medicine, University of Padova, Via Giustiniani, 2, 35128 Padua, Italy

2 Division of Gastroenterology, Hepatology and Nutrition, Department of Medicine, Virginia Commonwealth University and McGuire VA Medical Center, 1201 Broad Rock Boulevard, Richmond, VA 23249, USA

\section{Effect of Hepatic Encephalopathy (HE) on Health-Related Quality of Life (HRQOL)}

An impaired HRQOL is a major consequence of HE [4]. Across the spectrum from covert to overt HE, there have been multiple investigations (Table 1) that have highlighted the multifaceted impairment in this construct across studies and populations [1]. The tools used to interrogate HRQOL range from the shorter generic Short-Form 36 (SF-36) to the longer generic Sickness Impact Profile (SIP) and the liver-specific Chronic Liver Disease Questionnaire (CLDQ).

Most studies performed in HRQOL have used a combination of populations (covert and prior overt HE), as well as a variety of instruments [5]. The generic instrument most often used is the SF-36, which has a mental and physical component score. This instrument has 36 questions, and, due to the few questions and its generic nature, could underestimate subtle HRQOL changes. As shown in Table 1, studies that have failed to find an impact of HE on HRQOL are those that have used short, non-specific instruments such as the SF-36. On the other hand, studies that have focused on longer generic instruments such as the SIP, or liver-disease specific instruments such as the CLDQ, have mostly found a negative impact of HE on HRQOL. The SIP is a 136-question survey that enquires about health-related issues within $24 \mathrm{~h}$. It has two dimensions (psychological and physical) and 12 domains [6]. The CLDQ is a 29-question, 5-domain 
Table 1 Studies prospectively evaluating HRQOL without intervention/medication

\begin{tabular}{|c|c|c|}
\hline Study, year & Instrument used & $\begin{array}{l}\text { Poor QOL compared } \\
\text { with patients without } \\
\text { HE }\end{array}$ \\
\hline Groeneweg et al., 1998 [36] & Sickness Impact Profile & Yes \\
\hline Schomerus and Hamster, 2001 [37] & Sickness Impact Profile & Yes \\
\hline Arguedas et al., 2003 [4] & SF-36 & Yes \\
\hline Bao et al., 2007 [38] & Chronic Liver Disease Q, SF-36 & Yes \\
\hline Zhou et al., 2009 [39] & Chinese adaptation of QOL & Yes \\
\hline Les et al., 2010 [40] & Chronic Liver Disease Q, SF-36 & Yes \\
\hline Bajaj et al., 2011 [41] & $\begin{array}{l}\text { PROMIS tools and Sickness } \\
\text { Impact Profile }\end{array}$ & Yes \\
\hline Moscucci et al., 2011 [42] & SF-36 & No \\
\hline Parkash et al., 2012 [43] & Chronic Liver Disease Q & Yes \\
\hline Les et al., 2010 [40] & SF-36 & No \\
\hline Wunsch et al., 2013 [44] & Chronic Liver Disease Q, SF-36 & No \\
\hline Ahluwalia et al., 2013 [45] & Sickness Impact Profile & Yes \\
\hline Wang et al., 2013 [46] & Chinese HRQoL instrument & Yes \\
\hline Nardelli et al., 2013 [47] & SF-36 & Yes \\
\hline Thiele et al., 2013 [48] & Chronic Liver Disease Q & No \\
\hline Mina et al., 2014 [49] & Chronic Liver Disease Q & Yes \\
\hline Barboza et al., 2016 [50] & Specific and general questionnaires & Yes \\
\hline Paulson et al 2016 [51] & SF-36 & Yes \\
\hline Bajaj et al., 2016 [52] & PROMIS tools & Yes \\
\hline Patidar et al., 2017 [10] & PROMIS tools & Yes \\
\hline Labenz et al., 2018 [53] & Chronic Liver Disease Q & Yes \\
\hline
\end{tabular}

$S F$-36 Short-Form 36, PROMIS Patient-Reported Outcomes Measurement Information System, Chronic Liver Disease $Q$ Chronic liver disease questionnaire, $H R Q O L$ health-related quality of life, $Q O L$ quality of life, $H E$ hepatic encephalopathy

(abdominal symptoms, fatigue, systemic, activity, emotional function and worry) survey that enquires about changes over the last 2 weeks [7].

In studies of covert HE, where HRQOL changes are subtler than those found in prior overt $\mathrm{HE}$ patients, focused liver-specific questionnaires or longer generic questionnaires such as the SIP may be better in finding differences [5, 8]. HRQOL changes are important in predicting clinically relevant outcomes such as HE recurrence, hospitalizations, and death in outpatients with cirrhosis [9, 10]. Therefore, patient-reported outcomes pertaining to HRQOL should be considered integral to the prognostication and decisionmaking process.

\section{Association of HRQOL with Cognitive Impairment}

While covert $\mathrm{HE}$ is difficult to diagnose, it has multiple negative effects on daily function, progression to overt $\mathrm{HE}$, and survival [1]. Given the intricate relationship between covert HE and HRQOL, a few studies have used HRQOL questionnaires as a method of diagnosing covert HE [5].
These strategies are summarized in Table 2 [11-13]. This approach is of some practical relevance in the sense that well-being and a good prognosis are the ultimate aims of any diagnostic procedure. However, cognition and HRQOL should be assessed in parallel, and with pertinent tools, just as geriatricians do with cognition and daily living in patients with dementia [14]. An additional challenge with equating HRQOL with cognitive dysfunction is related to the direct effect of cirrhosis on HRQOL, with HE often reflecting worsening liver function [15].

\section{Burden of HE for Patients and Caregivers}

Unlike most other complications of cirrhosis, HE affects the entire family. Most caregivers of patients with $\mathrm{HE}$ are informal in nature, i.e. are not paid and are usually relatives who are mostly not prepared for this burden [16, 17]. The burden on the patient is characterized by high readmissions, worsening cognitive performance with each HE episode, and a decrease in independence [18-20]. This adds to the burden of HE on these caregivers and on the family, which spans medical, psychosocial, and financial domains [21]. 
Table 2 Using HRQOL to diagnose covert HE

\begin{tabular}{|c|c|c|c|c|}
\hline Study, year & Questionnaire & Covert HE strategy & Study design & Results \\
\hline Groeneweg et al., 2000 [13] & SIP individual questions & $\begin{array}{l}\text { EEG, Number Connection } \\
\text { Test A and Digit Symbol } \\
\text { Test }\end{array}$ & $\begin{array}{l}\text { Cross-sectional study with } \\
179 \text { outpatients }\end{array}$ & $\begin{array}{l}5 \text { questions of the SIP (I for- } \\
\text { get a lot, I spend much of } \\
\text { the day lying down, I have } \\
\text { difficulty doing handwork, } \\
\text { I am not working at all, } \\
\text { I am confused and start } \\
\text { several actions at a time), } \\
\text { sex, Child score and varices } \\
\text { were able to diagnose cov- } \\
\text { ert HE with } 90 \% \text { sensitivity }\end{array}$ \\
\hline Hirano et al., 2015 [12] & CLDQ & Paper-pencil tests & $\begin{array}{l}\text { Cross-sectional with } \\
\text { regression }(n=59) \text { in } \\
\text { outpatients }\end{array}$ & $\begin{array}{l}\text { CLDQ Worry domain was an } \\
\text { independent factor, with an } \\
\text { AUC of } 0.71\end{array}$ \\
\hline Nabi et al., 2014 [11] & SIP individual questions & Paper-pencil tests & $\begin{array}{l}\text { Cross-sectional and } \\
\text { longitudinal study of } 170 \\
\text { outpatients over } 1 \text { year }\end{array}$ & $\begin{array}{l}4 \text { questions of the SIP (I do } \\
\text { not maintain balance, I act } \\
\text { irritable or am impatient } \\
\text { with myself, I am not doing } \\
\text { any of my usual physical } \\
\text { recreation or activities, I } \\
\text { am eating much less than } \\
\text { usual), age and sex identi- } \\
\text { fied covert HE at baseline, } \\
6 \text { months and } 12 \text { months } \\
\text { with }>80 \% \text { sensitivity }\end{array}$ \\
\hline
\end{tabular}

$H R Q O L$ health-related quality of life, $H E$ hepatic encephalopathy, EEG electroencephalogram, SIP Sickness Impact Profile, $C L D Q$ Chronic Liver Disease Questionnaire

These changes worsen with the advancing spectrum from covert HE to overt HE, and are also more marked in older cirrhotic patients [17]. Therefore, the impact of HE and its impairment of daily function and HRQOL is not limited to the patient alone, and the entire family and their resources should be considered.

\section{Sleep Disorders and HE}

So-called sleep-wake inversion, or the combination of restless nights and excessive daytime sleepiness, was first described as a sign of overt HE by Sherlock et al. [22]. There is also anecdotal evidence that sleep abnormalities worsen following the insertion of transjugular intrahepatic portosystemic shunts [23], and improve after the initiation of ammonia-lowering treatment [24]. These findings have led to the idea that the pathogenesis of sleep-wake disturbances in patients with cirrhosis is closely related to that of HE, and that sleep and neuropsychiatric abnormalities are invariably associated in these patients; however, there is limited evidence to support this theory. In particular, both insomnia (i.e. difficulty falling asleep) and fragmented sleep, with multiple night awakenings, have often been reported in patients with cirrhosis and no or limited cognitive abnormalities [25, 26]. By contrast, there is more convincing evidence of an association between excessive daytime sleepiness and HE. For example, the absence of habitual daytime sleepiness (qualified as present/absent in everyday life) has been shown to have a negative predictive value of $92 \%$ in relation to the subsequent occurrence of HE-related hospitalizations over a follow-up period of 8 months [27]. Even more convincingly, changes in subjective sleepiness have been shown to closely parallel changes in blood ammonia levels in both healthy volunteers and patients with cirrhosis, in studies of hyperammonemia induced by an oral amino acid challenge (i.e. the oral administration of a mixture of amino acids that mimics the composition of blood, and therefore the increase in ammonia levels and the neuropsychiatric changes that are observed after a variceal bleed) [28]. These observations fit with the hypothesis that HE may be interpreted, at least to some extent, as a syndrome of decreased vigilance [29]. This interpretation of the syndrome has led to the attempt to combine ammonia-lowering and vigilance-enhancing medication. In a small pilot study, both drugs (L-ornithine L-aspartate and caffeine) were shown to contain the increase in ammonia levels/subjective sleepiness and electroencephalographic abnormalities in healthy volunteers, while their effect was less obvious in patients with cirrhosis [30]. However, the association of ammonia-lowering and vigilanceenhancing medication in the management of HE is worthy of further study. 


\section{Cognitive Reserve and Impact on HE and Quality of Life}

There are two opposing forces that determine the likelihood of expressing the HE phenotype/developing neuropsychiatric symptoms in the presence of hyperammonemia or in relation to cerebral insults of different types and sizescognitive reserve (i.e. the neuroprotection that derives from chronic mental, social, and physical activity) and neuropsychiatric comorbidity. Cognitive reserve represents a resilience factor, while comorbidity increases the likelihood of the phenotype becoming apparent. The first example of how cognitive reserve can modulate the HE phenotype in patients with cirrhosis was provided by Srivastava and colleagues, who described the case of a taxi driver with cirrhosis and significant psychometric impairment whose on-the-road driving test performance remained very good [31]. Several years later, Montagnese and colleagues reported the cases of two patients with cirrhosis and HE, whose hobby or job were possibly responsible for a selectively enhanced performance in one neuropsychiatric test [32]. Patel and colleagues subsequently reported better quality of life in patients with cirrhosis and higher cognitive reserve (assessed by a demographically based regression method to estimate pre-morbid intelligence in terms of index scores on the Wechsler Adult Intelligence Scale-Revised), regardless of the presence of covert HE and the degree of hepatic failure [33]. Finally, Amodio and colleagues [34] assessed cognitive reserve with a dedicated tool (the Cognitive Reserve Index questionnaire (CRIq) [35]) in a large group of well-characterized patients with cirrhosis and varying degrees of neuropsychiatric impairment. They reported a correlation between CRIq scores and neuropsychological performance, but not between CRIq and neurophysiological performance, suggesting that cognitive reserve may explain some of the mismatch between neuropsychological and neurophysiological $\mathrm{HE}$ indices, and may represent a resilience factor for neuropsychological dysfunction in these patients. While tools to measure cognitive reserve remain sparse, and their validation/use is not yet widespread, clinicians should be alert to the fact that personal inclinations and habits may impinge on neuropsychological performance, in some instances protecting from HE, and, in others, masking its milder phenotypic manifestations.

\section{Conclusions}

There is evidence that HE, even in its milder forms, affects quality of life, sleep-wake patterns, and the balance and relationships between the affected patient and their family.
The exact weight of HE over such life domains in relation to the underlying liver failure is not easily established, and the risk and resilience factors of single patients are difficult to measure. Hepatologists and gastroenterologists should become more familiar with the tools and techniques needed to further the understanding within this field of clinical research and clinical practice, which has significant social and economic ramifications.

\section{Compliance with Ethical Standards}

Funding and Conflict of Interest Jasmohan Bajaj is partly supported by VA Merit Review I0CX001076 and NIH NCATS R21TR002024. Sara Montagnese, in her role as Principal Investigator within the Department of Medicine of Padova University Hospital, has received research funding from Merz Pharmaceuticals GmbH. This article has been published in a special edition journal supplement wholly funded by Merz Pharmaceuticals GmbH, Frankfurt, Germany.

Open Access This article is distributed under the terms of the Creative Commons Attribution-NonCommercial 4.0 International License (http://creativecommons.org/licenses/by-nc/4.0/), which permits any noncommercial use, distribution, and reproduction in any medium, provided you give appropriate credit to the original author(s) and the source, provide a link to the Creative Commons license, and indicate if changes were made.

\section{References}

1. Vilstrup H, Amodio P, Bajaj J, Cordoba J, Ferenci P, Mullen KD, et al. Hepatic encephalopathy in chronic liver disease: 2014 Practice Guideline by the American Association for the Study of Liver Diseases and the European Association for the Study of the Liver. Hepatology. 2014;60(2):715-35.

2. Conn HO, Leevy CM, Vlahcevic ZR, Rodgers JB, Maddrey WC, Seeff $\mathrm{L}$, et al. Comparison of lactulose and neomycin in the treatment of chronic portal-systemic encephalopathy. A double blind controlled trial. Gastroenterology. 1977;72(4 Pt 1):573-83.

3. Bajaj JS, Cordoba J, Mullen KD, Amodio P, Shawcross DL, Butterworth RF, et al. Review article: the design of clinical trials in hepatic encephalopathy: an International Society for Hepatic Encephalopathy and Nitrogen Metabolism (ISHEN) consensus statement. Aliment Pharmacol Ther. 2011;33(7):739-47.

4. Arguedas MR, DeLawrence TG, McGuire BM. Influence of hepatic encephalopathy on health-related quality of life in patients with cirrhosis. Dig Dis Sci. 2003;48(8):1622-6.

5. Agrawal S, Umapathy S, Dhiman RK. Minimal hepatic encephalopathy impairs quality of life. J Clin Exp Hepatol. 2015;5(Suppl 1):S42-8.

6. Bergner M, Bobbitt RA, Carter WB, Gilson BS. The Sickness Impact Profile: development and final revision of a health status measure. Med Care. 1981;19(8):787-805.

7. Younossi ZM, Guyatt G, Kiwi M, Boparai N, King D. Development of a disease specific questionnaire to measure health related quality of life in patients with chronic liver disease. Gut. 1999;45(2):295-300.

8. Prasad S, Dhiman RK, Duseja A, Chawla YK, Sharma A, Agarwal R. Lactulose improves cognitive functions and health-related quality of life in patients with cirrhosis who have minimal hepatic encephalopathy. Hepatology. 2007;45(3):549-59. 
9. Kanwal F, Gralnek IM, Hays RD, Zeringue A, Durazo F, Han SB, et al. Health-related quality of life predicts mortality in patients with advanced chronic liver disease. Clin Gastroenterol Hepatol. 2009;7(7):793-9.

10. Patidar KR, Thacker LR, Wade JB, White MB, Gavis EA, Fagan A, et al. Symptom domain groups of the patient-reported outcomes measurement information system tools independently predict hospitalizations and re-hospitalizations in cirrhosis. Dig Dis Sci. 2017;62(5):1173-9.

11. Nabi E, Thacker LR, Wade JB, Sterling RK, Stravitz RT, Fuchs M, et al. Diagnosis of covert hepatic encephalopathy without specialized tests. Clin Gastroenterol Hepatol. 2014;12(8):1384-9.e2.

12. Hirano H, Saito M, Yano Y, Momose K, Yoshida M, Tanaka A, et al. Chronic Liver Disease Questionnaire would be a primary screening tool of neuropsychiatric test detecting minimal hepatic encephalopathy of cirrhotic patients. Hepatol Res. 2015;45(9):994-1003.

13. Groeneweg M, Moerland W, Quero JC, Hop WC, Krabbe PF, Schalm SW. Screening of subclinical hepatic encephalopathy. J Hepatol. 2000;32(5):748-53.

14. Katz S, Ford AB, Moskowitz RW, Jackson BA, Jaffe MW. Studies of illness in the aged. The index of the ADL: a standardized measure of biological and psychosocial function. JAMA. 1963;185:914-9.

15. Marchesini G, Bianchi G, Amodio P, Salerno F, Merli M, Panella $\mathrm{C}$, et al. Factors associated with poor health-related quality of life of patients with cirrhosis. Gastroenterology. 2001;120(1):170-8.

16. Bajaj JS, Wade JB, Gibson DP, Heuman DM, Thacker LR, Sterling RK, et al. The multi-dimensional burden of cirrhosis and hepatic encephalopathy on patients and caregivers. Am J Gastroenterol. 2011;106(9):1646-53.

17. Rakoski MO, McCammon RJ, Piette JD, Iwashyna TJ, Marrero JA, Lok AS, et al. Burden of cirrhosis on older Americans and their families: analysis of the health and retirement study. Hepatology. 2012;55(1):184-91.

18. Volk ML, Tocco RS, Bazick J, Rakoski MO, Lok AS. Hospital readmissions among patients with decompensated cirrhosis. Am J Gastroenterol. 2012;107(2):247-52.

19. Bajaj JS, Reddy KR, Tandon P, Wong F, Kamath PS, Garcia-Tsao $\mathrm{G}$, et al. The 3-month readmission rate remains unacceptably high in a large North American cohort of patients with cirrhosis. Hepatology. 2016;64(1):200-8.

20. Montagnese S, Amato E, Schiff S, Facchini S, Angeli P, Gatta A, et al. A patients' and caregivers' perspective on hepatic encephalopathy. Metab Brain Dis. 2012;27(4):567-72.

21. Bajaj JS, Riggio O, Allampati S, Prakash R, Gioia S, Onori E, et al. Cognitive dysfunction is associated with poor socioeconomic status in patients with cirrhosis: an international multicenter study. Clin Gastroenterol Hepatol. 2013;11(11):1511-6.

22. Sherlock S, Summerskill WH, White LP, Phear EA. Portal-systemic encephalopathy; neurological complications of liver disease. Lancet. 1954;267(6836):454-7.

23. Wiltfang J, Nolte W, von Heppe J, Bahn E, Pilz J, Hajak G, et al. Sleep disorders and portal-systemic encephalopathy following transjugular intrahepatic portosystemic stent shunt in patients with liver cirrhosis. Relation to plasma tryptophan. Adv Exp Med Biol. 1999;467:169-76.

24. Bergonzi P, Bianco A, Mazza S, Mennuni G, Zolo P. Organization of nocturnal sleep in patients with liver cirrhosis: changes before and after treatment with levodopa and lactulose [in Italian]. Riv Neurol. 1975;45:118-23.

25. Montagnese S, Middleton B, Skene DJ, Morgan MY. Night-time sleep disturbance does not correlate with neuropsychiatric impairment in patients with cirrhosis. Liver Int. 2009;29(9):1372-82.
26. Cordoba J, Cabrera J, Lataif L, Penev P, Zee P, Blei AT. High prevalence of sleep disturbance in cirrhosis. Hepatology. 1998;27(2):339-45.

27. De Rui M, Schiff S, Aprile D, Angeli P, Bombonato G, Bolognesi $\mathrm{M}$, et al. Excessive daytime sleepiness and hepatic encephalopathy: it is worth asking. Metab Brain Dis. 2013;28(2):245-8.

28. Bersagliere A, Raduazzo ID, Nardi M, Schiff S, Gatta A, Amodio $\mathrm{P}$, et al. Induced hyperammonemia may compromise the ability to generate restful sleep in patients with cirrhosis. Hepatology. 2012;55(3):869-78.

29. Montagnese S, Turco M, Amodio P. Hepatic encephalopathy and sleepiness: an interesting connection? J Clin Exp Hepatol. 2015;5(Suppl 1):S49-53.

30. Garrido M, Skorucak J, Raduazzo D, Turco M, Spinelli G, Angeli $\mathrm{P}$, et al. Vigilance and wake EEG architecture in simulated hyperammonaemia: a pilot study on the effects of L-ornithine-L-aspartate (LOLA) and caffeine. Metab Brain Dis. 2016;31(4):965-74.

31. Srivastava A, Mehta R, Rothke SP, Rademaker AW, Blei AT. Fitness to drive in patients with cirrhosis and portal-systemic shunting: a pilot study evaluating driving performance. J Hepatol. 1994;21(6): 1023-8.

32. Montagnese S, Cona G, Schiff S, Maresio G, Gatta A, Merkel C, et al. The hunter and the pianist: two hepatic encephalopathy tales. J Clin Gastroenterol. 2011;45(6):563-6.

33. Patel AV, Wade JB, Thacker LR, Sterling RK, Siddiqui MS, Stravitz RT, et al. Cognitive reserve is a determinant of healthrelated quality of life in patients with cirrhosis, independent of covert hepatic encephalopathy and model for end-stage liver disease score. Clin Gastroenterol Hepatol. 2015;13(5):987-91.

34. Amodio P, Montagnese S, Spinelli G, Schiff S, Mapelli D. Cognitive reserve is a resilience factor for cognitive dysfunction in hepatic encephalopathy. Metab Brain Dis. 2017;32(4):1287-93.

35. Nucci M, Mapelli D, Mondini S. Cognitive Reserve Index questionnaire (CRIq): a new instrument for measuring cognitive reserve. Aging Clin Exp Res. 2012;24(3):218-26.

36. Groeneweg M, Quero JC, De Bruijn I, Hartmann IJ, Essink-bot ML, Hop WC, et al. Subclinical hepatic encephalopathy impairs daily functioning. Hepatology. 1998;28(1):45-9.

37. Schomerus H, Hamster W. Quality of life in cirrhotics with minimal hepatic encephalopathy. Metab Brain Dis. 2001;16(1-2):37-41.

38. Bao ZJ, Qiu DK, Ma X, Fan ZP, Zhang GS, Huang YQ, et al. Assessment of health-related quality of life in Chinese patients with minimal hepatic encephalopathy. World J Gastroenterol. 2007;13(21):3003-8.

39. Zhou YQ, Chen SY, Jiang LD, Guo CY, Shen ZY, Huang PX, et al. Development and evaluation of the quality of life instrument in chronic liver disease patients with minimal hepatic encephalopathy. J Gastroenterol Hepatol. 2009;24(3):408-15.

40. Les I, Doval E, Flavia M, Jacas C, Cardenas G, Esteban R, et al. Quality of life in cirrhosis is related to potentially treatable factors. Eur J Gastroenterol Hepatol. 2010;22(2):221-7.

41. Bajaj JS, Thacker LR, Wade JB, Sanyal AJ, Heuman DM, Sterling RK, et al. PROMIS computerised adaptive tests are dynamic instruments to measure health-related quality of life in patients with cirrhosis. Aliment Pharmacol Ther. 2011;34(9):1123-32.

42. Moscucci F, Nardelli S, Pentassuglio I, Pasquale C, Ridola L, Merli M, et al. Previous overt hepatic encephalopathy rather than minimal hepatic encephalopathy impairs health-related quality of life in cirrhotic patients. Liver Int. 2011;31(10):1505-10.

43. Parkash O, Iqbal R, Jafri F, Azam I, Jafri W. Frequency of poor quality of life and predictors of health related quality of life in cirrhosis at a tertiary care hospital Pakistan. BMC Res Notes. 2012;5:446.

44. Wunsch E, Szymanik B, Post M, Marlicz W, Mydlowska M, Milkiewicz P. Minimal hepatic encephalopathy does not impair 
health-related quality of life in patients with cirrhosis: a prospective study. Liver Int. 2011;31(7):980-4.

45. Ahluwalia V, Wade JB, Thacker L, Kraft KA, Sterling RK, Stravitz RT, et al. Differential impact of hyponatremia and hepatic encephalopathy on health-related quality of life and brain metabolite abnormalities in cirrhosis. J Hepatol. 2013;59(3):467-73.

46. Wang JY, Zhang NP, Chi BR, Mi YQ, Meng LN, Liu YD, et al. Prevalence of minimal hepatic encephalopathy and quality of life evaluations in hospitalized cirrhotic patients in China. World $\mathbf{J}$ Gastroenterol. 2013;19(30):4984-91.

47. Nardelli S, Pentassuglio I, Pasquale C, Ridola L, Moscucci F, Merli M, et al. Depression, anxiety and alexithymia symptoms are major determinants of health related quality of life (HRQoL) in cirrhotic patients. Metab Brain Dis. 2013;28(2):239-43.

48. Thiele M, Askgaard G, Timm HB, Hamberg O, Gluud LL. Predictors of health-related quality of life in outpatients with cirrhosis: results from a prospective cohort. Hepat Res Treat. 2013;2013:479639.

49. Mina A, Moran S, Ortiz-Olvera N, Mera R, Uribe M. Prevalence of minimal hepatic encephalopathy and quality of life in patients with decompensated cirrhosis. Hepatol Res. 2014;44(10):E92-9.
50. Barboza KC, Salinas LM, Sahebjam F, Jesudian AB, Weisberg IL, Sigal SH. Impact of depressive symptoms and hepatic encephalopathy on health-related quality of life in cirrhotic hepatitis $\mathrm{C}$ patients. Metab Brain Dis. 2016;31(4):869-80.

51. Paulson D, Shah M, Miller-Matero LR, Eshelman A, Abouljoud M. Cognition predicts quality of life among patients with endstage liver disease. Psychosomatics. 2016;57(5):514-21.

52. Bajaj JS, White MB, Unser AB, Ganapathy D, Fagan A, Gavis EA, et al. Cirrhotic patients have good insight into their daily functional impairment despite prior hepatic encephalopathy: comparison with PROMIS norms. Metab Brain Dis. 2016;31(5):1199-203.

53. Labenz C, Baron JS, Toenges G, Schattenberg JM, Nagel M, Sprinzl MF, et al. Prospective evaluation of the impact of covert hepatic encephalopathy on quality of life and sleep in cirrhotic patients. Aliment Pharmacol Ther. 2018;48(3):313-21. 